\title{
The Design of Corporate Debt Structure and Bankruptcy*
}

\author{
Ernst-Ludwig von Thadden ${ }^{1}$ \\ Erik Berglöf $^{2} \quad$ Gérard Roland ${ }^{3}$
}

Final version: October 2009

Forthcoming: Review of Financial Studies

Includes unpublished technical appendix

* We are grateful to the Center for Advanced Studies in the Behavioral Sciences, Stanford, for providing a stimulating environment for early discussions about the topic of this paper. Thadden thanks the German National Research Foundation (DFG) for support. We thank two anonymous referees for their detailed comments. We benefited from discussions and suggestions from Ron Anderson, Lucian Bebchuk, Bernard Black, Patrick Bolton, Eric Maskin, Katharina Pistor, Howard Rosenthal, Yossi Spiegel, Javier Suarez, Jean Tirole, and in particular, Oliver Hart, as well as from several seminar and conference audiences.

${ }^{1}$ Corresponding author, Universität Mannheim, ECGI, and CEPR, email: vthadden@uni-mannheim.de.

${ }^{2}$ Stockholm School of Economics, European Bank for Reconstruction and Development, CEPR and WDI.

${ }^{3}$ University of California at Berkeley and CEPR 


\begin{abstract}
:
This paper integrates the problem of designing corporate bankruptcy rules into a theory of optimal debt structure. We show that, in an optimal contracting framework with imperfect renegotiation, having multiple creditors increases a firm's debt capacity while increasing its incentives to default strategically. The optimal debt contract gives creditors claims that are jointly inconsistent in case of default. Bankruptcy rules are therefore a necessary part of the overall financing contract, to make claims consistent and to prevent a value reducing run for the assets of the firm. We characterize these rules, with predictions about the allocation of security rights, the right to trigger bankruptcy and the symmetry of treatment of creditors in default.
\end{abstract}

Keywords: Bankruptcy, Debt Structure, Contracts.

JEL Classification: G3, K2. 
Bankruptcy law regulates the interaction between debtors and creditors when debtors default and the parties cannot work out their differences outside the courts. The law addresses two main types of conflicts: conflicts between a debtor and her creditors, and conflicts among creditors themselves. Empirically, this latter type of conflict is the major source of complexity in modern bankruptcy law, and has therefore given rise to a substantial literature, much of which in law. This literature typically takes an ex-post perspective: how to sort out claims once the firm is bankrupt, given the contractual and legal arrangements in place. But the way ex-post conflicts are resolved also influences the initial financing and valuation of the firm, which suggests that the two problems should be analyzed jointly. In fact, the problem of bankruptcy is most interesting when posed in an ex-ante framework as it raises what seems like a paradox: if bankruptcy with multiple creditors is so complex, why would a firm contract with several creditors in the first place? Put differently: if conflicts of interest must be resolved ex post anyhow and these resolutions are costly, why create them and how structure them ex ante? We attempt to answer these questions in an optimal contracting approach to corporate debt and bankruptcy.

The paper analyzes a firm's choice of debt structure and its effect on incentives for strategic default. We start from the observation that multiple creditors make contract renegotiations more difficult and emphasize a) the ex-post conflicts among multiple creditors, b) the design of individual claims and their impact on these conflicts and c) the role of bankruptcy rules in resolving such conflicts from an ex ante perspective. In our model, having multiple creditors gives rise to potential ex-post inefficiency, which stems from frictions in multilateral conflict resolution. This corresponds to the well-known inefficiencies in the workouts of financial distress, documented, e.g., by Asquith, Gertner, and Scharfstein (1994). However, in the spirit of the literature on strategic capital structure design, ${ }^{1}$ we note that this ex-post inefficiency also has a positive incentive effect, as it forces the firm to honor several claims instead of only one if it wants to avoid the ex-post inefficiency.

To provide an intuition for why two investors are better than one in our model, consider a firm seeking outside finance from two investors. Following Hart and Moore (1998), we describe the moral-hazard problem of the firm in repaying its financiers by assuming that the project generates some un-

\footnotetext{
${ }^{1}$ See, in particular, Hart and Moore (1998), Bolton and Scharfstein (1996), Dewatripont and Tirole (1994), Berglöf and von Thadden (1994).
} 
verifiable cash flows next to the verifiable assets. In this setup, repayment is limited by how much asset value the financiers can credibly threaten to liquidate. Under perfect renegotiation (or with one single creditor), the firm's commitment ability is in principle given by the amount of assets available for foreclosure should the firm default. However, this constraint is relaxed if the firm is forced to renegotiate individually with its creditors. If this is the case, the firm can promise ex ante up to the full amount of available assets to each one of the investors. When the firm only defaults on one investor ex post, this investor has the right to foreclose on the firm's assets to collect her debt. As each creditor has this individual right, the firm must pay out twice its asset value if it wants to protect its assets. Hence, a renegotiation with two creditors credibly commits the firm to pay out twice in order to avoid renegoatiation. These higher repayment obligations, however, also increase the incentives for strategic default, in which case the inefficiency of the creditor interaction ex post destroys value. This creates a counterveiling force to the commitment effect of high individual debt claims and thus leads to a tradeoff in the design of these claims.

If the firm defaults on both creditors, and one creditor calls the sheriff to enforce the payment, the firm or the other creditor can file for bankruptcy. In this case, the sum of the two claims are larger than the available amount of verifiable assets, and individual claims must be adjusted. This is the essential role of bankruptcy in our model. Bankruptcy provides a means to pare down individual claims if the debtor is unable or unwilling to honor them and the creditors must confiscate what is available. We thus emphasize the view, shared by many scholars of law and economics, but rarely modeled in full, that "bankruptcy is a situation in which existing claims are inconsistent" (Hart, 1995).

Our model is the first to bring out the distinction between debt collection and bankruptcy that is a fundamental feature of debt finance in practice and legal theory. Debt collection law is basically bilateral and defines the rights of a single creditor in a bilateral conflict with the debtor. In our model, each creditor has the right to collect his debt if the debtor defaults against him, and as every creditor wields this threat, the debtor is under strong pressure to pay out. Yet, if the debtor defaults against several creditors, these threats cannot necessarily be executed simultaneously, individual debt collection ceases, and the debtor is in bankruptcy. In this sense, we model bankruptcy as "collective debt collection" (Jackson, 1986).

Next to the distinction between individual and collective debt collection, 
our model yields the following empirical predictions.

The model predicts that debt claims should be "undersecured", i.e., that nominal debt claims should be larger than what creditors receive in bankruptcy. While this is a standard consequence of single-creditor models, it is not obvious in a multi-creditor model. In our model this result is true because, holding total bankruptcy payout constant, too high a bankruptcy payout for one creditor would give other creditors so little in bankruptcy that the firm has incentives to strategically default against them (which is not ex ante optimal, as we show). Our prediction is consistent with standard practice and the empirically documented observation in many countries of systematically low retrieval rates of creditors in bankruptcy (see, e.g., Weiss (1990)).

Further, the model predicts that for a range of borrowing requirements, the debtor should retain some of her assets in bankruptcy. In our model, this is true because the debtor on average uses the firm's assets more efficiently. Hence, even if ex post the debtor has bad prospects, the ex ante allocation of security rights should protect the debtor. As a corollary, absolute priority the notion that creditors must be satisfied fully in bankruptcy before owners are to retain something - can be violated in the present model. Again, this is consistent with the empirical literature (see, e.g., Franks and Torous (1989) and Bharath, Panchapegesan, and Werner (2008)).

Next, the model predicts that all creditors should optimally be treated symmetrically ex post, in the sense that either all creditors are repaid or all are defaulted upon. In our model, this is true because unilateral foreclosures by one creditor that impair the value of claims of other creditors do not minimize expected liquidation and are therefore value-reducing ex ante. This corresponds to, and gives an efficiency justification for, the widespread use of "equal treatment" rules in bankruptcy legislation, such as the Trust Indenture Act in the U.S.

Furthermore, our model allows to distinguish between liquidity-driven defaults and value-driven defaults. In the equilibrium of the model, firms default either because they lack liquidity but are fundamentally sound or because they have liquidity but little long-term value. In our model, valuedriven default can occur in equilibrium because it can be optimal ex ante to contract high face values of debt (to extract much cash on average in order to keep overall liquidation low), which in turn makes strategic default optimal in some ex-post contingencies. Davydenko (2005) provides evidence that empirically both motives are important and have independent explanatory 
power.

Our simple model of bankruptcy captures some important elements of existing bankruptcy procedures. We show that each creditor's right to liquidate assets, which protects him against opportunism by the debtor, must be complemented by the right to trigger bankruptcy, which in turn limits the individual liquidation rights. Bankruptcy is triggered when a creditor files to prevent his claims from being eroded through debt collection of other creditors. The procedure demands an "automatic stay" ensuring that liquidation claims are executed simultaneously, and distributes liquidation values according to a pre-specified rule. Interestingly, however, giving the creditors the right to trigger bankruptcy is not always sufficient to rule out runs for the assets. If individual creditors stand to gain relatively little from bankruptcy, but recover their full debt claim if they are the first to foreclose individually, they may have an incentive not to trigger bankruptcy ex post, but rather run for the assets. In such a constellation it is optimal to give the debtor the right to trigger bankruptcy. In this respect, our model provides a new efficiency argument for debtor-friendly bankruptcy legislation (see Baird, 1991).

The remainder of this paper is organized as follows. In Section 1, we review some of the literature on debt structure and bankruptcy. Section 2 describes the basic structure of the model. Section 3 studies optimal contracting under the assumption that bankruptcy is triggered automatically. Section 4 extends the model and provides a more detailed institutional analysis of the bankruptcy process, in particular the right to trigger bankruptcy and equal treatment rules. Section 5 concludes with a discussion of the role of contracts versus the law and further research avenues. Some proofs are contained in the appendix.

\section{Related Literature}

Our paper touches on two large strands of the literature that up to now have rarely been brought together: the literature on corporate bankruptcy and on capital structure. Here we review some contributions to both strands that are relevant to our analysis.

An important part of the large literature on bankruptcy law focuses on optimal procedural and substantial rules, taking as given pre-existing debt contracts and the decision to enter bankruptcy (next to the large legal literature, see, e.g., Bebchuk (1988), Aghion, Hart and Moore (1992) or Baird 
and Bernstein (2005)). This work rightly points out that the choice of debt structure influences what happens and what should happen in bankruptcy. Yet, it is silent on the determinants of debt structure, which is problematic as the bankruptcy procedure has an impact on the firm's capital structure decision. An important exception is the work by Harris and Raviv (1995) who study the impact of different games played ex post on the ex-ante efficiency of the contract. Different from our work, however, Harris and Raviv (1995) are only concerned with games between the debtor and one single investor.

Another interesting avenue of research has looked at the bankruptcy problem from an ex-ante perspective. Contributions such as those by Bebchuk (2002), Berkovitch and Israel (1999), Cornelli and Felli (1997), Schwartz (1998) or Acharya, John, and Sundaram (2010) analyse the impact of bankruptcy on debtors' investments, debt levels, and incentives prior to bankruptcy. These ex-ante analyses are not concerned with the key question of our paper, which is the role of multiple creditors in bankruptcy. In fact, all of these articles consider the conflict between a debtor and a single representative creditor.

Conceptually, our work is closest to the legal literature on bankruptcy, which emphasizes that the main role of bankruptcy law "is that of bankruptcy as a collective debt-collection device, and it deals with the rights of creditors ... inter se" (Jackson, 1986). For example, Kordana and Posner (1999) study the complex voting features associated with Chapter 11 in the U.S. bankruptcy code. Similar to our paper, they discuss the tradeoff between reducing the cost of liquidation by lowering individual pre-bankruptcy entitlements and discouraging strategic default. However, like most of the legal literature, they do not formally model the full ex-ante contracting problem, which makes it difficult to evaluate the effects they are discussing.

There are only very few papers that have modelled multiple creditor problems from an ex-ante perspective. Of interest in our context are, in particular, the contributions by Winton (1995), Bolton and Scharfstein (1996), Bris and Welch (2005), Hege and Mella-Barral (2005), Bisin and Rampini (2006), and Hackbarth, Hennessy, and Leland (2007).

In Bolton and Scharfstein's (1996) seminal theory of debt structure, borrowing from multiple sources can be optimal, but need not. In their model, multiple (two) creditors increase firm value on the one hand because of increased bargaining pressure in strategic default, but decrease firm value on the other hand because of less efficient continuation choices in liquidity default. The optimal number of creditors emerges as a trade-off between these 
two tendencies. Their analysis does not consider the key problem of our paper, the ex-post tension between individual and collective liquidation rights of creditors. As a consequence, they are not concerned with the optimal allocation of individual collection and security rights and their impact on default and bankruptcy.

Bris and Welch (2005) take a different approach to the coordination problem between multiple creditors in ex-post bargaining. They note that such bargaining is wasteful because of lobbying and other dead-weight losses, but that free-riding reduces the incentives for such wasteful activities when the number of creditors increases. Hence, although payments to creditors in financial distress decrease with the number of creditors, this is priced in the debt claims ex ante and only the beneficial effect of reduced influence costs ex post matters, which creates a tendency to contract with multiple creditors. Differently from our theory, Bris and Welch (2005) ignore the problem of strategic default, by simply assuming that the debtor pays out in good states of nature. Our theory is consistent with theirs in that we emphasize the advantage of contracting with multiple creditors, but we differ from their theory by pointing out the downside of multiple creditors when it comes to strategic default. Our theory of the design of individual debt claims and the role of bankruptcy is driven by the tension between collective and individual creditor rights, which is absent in their model.

Winton (1995) approaches the problem of multiple creditors from the perspective of costly state verification, generalizing the work of Townsend (1979) and Gale and Hellwig (1985). His results provide a theoretical rationale for seniority and absolute priority, and predict an ordering of monitoring activities among investors. These monitoring activities are reactions to financial distress and can therefore be interpreted as gradual bankruptcy provisions. Different from our work, in Winton (1995) the debtor borrows from several creditors by assumption. ${ }^{2}$

Bisin and Rampini (2006) are interested in the ex-ante incentive effects of bankruptcy in an environment in which a debtor can borrow from several lenders to smooth consumption. They show that a bankruptcy-like contract allows the main lender to relax the debtor's incentive compatibility constraint, because it is a means for the main lender to commit to confiscate

\footnotetext{
${ }^{2}$ It is actually interesting to note that Winton (1995) himself plays down the link of his theory to bankruptcy. He rather stresses examples such as asset securitization or reinsurance, where the individual verification activities do not necessarily imply that a joint "bankruptcy" decision is negotiated and implemented.
} 
returns in low-return states (which is not optimal for consumption smoothing reasons, but increases the borrower's effort incentives). Different from our model, in their model lending is for consumption smoothing and not production (so the focus is rather on consumer bankruptcy), and exclusive lending contracts are superior to contracts with multiple creditors, but cannot be enforced by assumption.

Hege and Mella-Barral (2005) and Hackbarth, Hennessy and Leland (2007) consider continuous-time models of debt renegotiation with multipe creditors. Like in our model, equity can make opportunistic debt exchange offers to force concessions on coupon payments. Different from our paper, however, Hege and Mella-Barral (2005) assume that all debt claims are ex-ante identical and do not study the design of individual claims and its relationship with bankruptcy. Hackbarth, Hennessy, and Leland (2007) extend the work by Hege and Mella-Barral (2005) by assuming that there are two types of debt, market debt and bank debt. Bank debt can be costlessly and efficiently renegotiated, while market debt cannot be renegotiated at all. Ideally, firms would only contract bank debt, but that claim is limited by the firm's collateral value. In order to increase debt-capacity, firms must take out market debt. The paper shows in particular, that optimally both types of debt coexist. Thus, Hackbarth, Hennessy, and Leland (2007) study how exogenously different types of debt coexist, while our paper makes no a priori assumptions about debt characteristics and derives the differentiation of individual claims and their treatment in bankruptcy endogenously.

\section{The Model}

A firm can invest a fixed amount $I$ at date 0 and lives for two periods after that date. As in the "incomplete contracts" literature on debt contracts following Hart and Moore (1998), at date 1, the firm has assets in place worth $A$ that generate a cash flow $Y$. Asset value $A$ at date 1 is verifiable and deterministic, known to everybody in advance. Cash flow, $Y$, is observable, but not verifiable, and accrues to the firm's management. The difference between $A$ and $Y$ is that foreclosure on the firm's property by the sheriff can only reach $A$, not $Y$. Hence, while contractual transfers of assets in place can be enforced by courts, transfers of cash must be incentive-compatible for the firm.

If the firm is not liquidated at date 1 , final firm value $V$ is realized at 
date 2, where $V$ is a continuous random variable with cumulative distribution function $F(V)$ and support $[\underline{V}, \bar{V}]$. We assume that $F$ is differentiable on $(\underline{V}, \bar{V})$ with density $f$, and extend $F$ to $F(V)=0$ on $[0, \underline{V}]$ if $\underline{V}>0 .{ }^{3}$ In this paper we assume for simplicity that all of $V$ is non-verifiable, i.e. that management cannot credibly promise to transfer value to creditors at date 2 . Hence, we focus on short-term debt and ignore issues such as debt maturity structure and debt rescheduling. ${ }^{4}$

At date 1 , there is a public signal $v$ about $V$. To simplify the presentation (no loss of generality here), we assume that the signal is perfect, i.e. that $V$ is known already at date 1 . At date 1 , assets in place can be liquidated. If $B \leq A$ is the total amount liquidated, the firm continues on the scale $(1-B / A)$. This means that the firm and its owners obtain $(1-B / A) V$ at date 2. This assumption amounts to assuming that long-term firm value is produced with constant returns to scale. ${ }^{5}$

Interest rates across periods are normalized to 0 . In order to simplify the presentation, we assume that it is always inefficient to liquidate assets in place:

$$
\underline{V} \geq A \text {. }
$$

This assumption describes the more interesting case of the bankruptcy problem: although this is inefficient ex post, the parties may be forced to liquidate assets in order to motivate the debtor to repay. All our results hold in the more general case of arbitrary $\underline{V} \geq 0$. (see the appendix).

Short term cash flow $Y$, realized at date 1 , is given by

$$
Y= \begin{cases}0 & \text { with probability } 1-q \\ Y_{H} & \text { with probability } q\end{cases}
$$

Here $Y=0$ represents the situation in which the firm is liquidity-constrained, and $Y=Y_{H}$ the case of no liquidity constraints. To simplify, we assume that cash flows in the the good state are sufficiently high so as to avoid any liquidity constraints in that state. For reasons that will become clear soon (we focus on the case of two creditors), we impose

$$
Y_{H} \geq 2 A
$$

\footnotetext{
${ }^{3}$ Hence, management can always claim at date 2 that it has nothing to pay out (although this is a zero-probability event, it can occur).

${ }^{4}$ See Gertner and Scharfstein (1991) and Berglöf and von Thadden (1994) for models that address some of these issues.

${ }^{5}$ As for example in Hart and Moore (1998) and Harris and Raviv (1995).
} 
At date 0 , the firm is run by a risk-neutral owner/manager who has no funds and raises them from external investors. Investors are risk-neutral and competitive, they each put up $I_{i}>0, \sum I_{i} \geq I, i=1, \ldots, n$. We shall focus here on the case of two creditors. We discuss in the conclusion how the analysis extends to $n$ creditors.

In order to capture more of the richness of multilateral debt contracts in practice, we go beyond the basic incentive-efficient contracting framework and allow for renegotiation. We model renegotiation as a simple bilateral take-it-or-leave-it offer game between the firm and each creditor, a set up that corresponds to a simple form of exchange offers. ${ }^{6}$ The fact that bargaining is bilateral represents the frictions that are inherent in typical out-of-court bargaining and means that the creditors as a group cannot get together with the firm to negotiate their way efficiently around bankruptcy. There is substantial empirical evidence on the difficulty of out-of-court agreements. Among others, Gilson, John, and Lang (1990), and Asquith, Gertner, and Scharfstein (1994) find that out-of-court restructurings have a substantial risk of failure, and this risk is the higher, the larger the number of creditors, in particular public debtholders. Gilson (1997) argues that the relatively high transactions costs of private restructurings that he finds (compared to Chapter 11 cases) are the result of unanimity requirements and coordination problems in out-of-court settlements.

At date 0 , the firm and the creditors sign a contract and investor $i$ pays $I_{i}$ to the firm. The latter promises a repayment of $R_{i}$ to investor $i$. The contract contains an individual foreclosure right $D_{i} \leq A$, which can be collected if only creditor $i$ forecloses, and individual claims $B_{i}$ under collective debt collection, with $B_{1}+B_{2} \leq A$. Apart from these constraints, we place no a priori restriction on $B_{i}$ and $D_{i}$. In particular, we do not restrict $D_{i}$ and $B_{i}$ to be equal: investor claims under individual foreclosure and under collective debt collection can differ.

At date 1, nature determines $Y$ and $V$. Since we allow for renegotiation, the firm then offers each creditor separately to pay $p_{i} \leq R_{i}, i=1,2$. If $p_{i}=R_{i}$, creditor $i$ has no more claim against the firm. If $p_{i}<R_{i}$ for one or both creditors, these creditors simultaneously and separately choose to accept the payment (strategy $a$ ) or to foreclose on the firm's assets (strategy $f$ ). If only one creditor accepts the firm's cash offer and the other forecloses,

\footnotetext{
${ }^{6}$ See Detriagache and Garella (1996) for an ex-post analysis of exchange offers (that does not address the ex-ante problems we discuss here).
} 
the latter receives $D_{i}$ whereas if both foreclose, they each receive $B_{i}$.

This model of individual versus collective liquidation rights adds a new, more realistic dimension to the contracting problem. In practice, debt contracts typically specify individual, non-interactive collection rights, which are governed by debt collection law, and are less specific concerning collective debt collection. This problem is addressed by covenants, priority rules or collateral assignments, but many interactive collection rights of creditors are left to bankruptcy law and judges, as a way to implement multilateral debt collection. Our approach to modelling these decisions in this and the next section is to ask what a contract would optimally stipulate if it included complete provisions for multilateral debt collection and if these provisions were executed automatically as soon as both creditors decide to foreclose on the firm's assets. Such multilateral debt collection therefore is akin to bankruptcy. In Section 4, we will investigate the bankruptcy problem more deeply by asking how such multilateral debt collection can be implemented if it does not happen automatically.

A contract in this renegotiation framework thus is given by eight nonnegative numbers $\left(I_{1}, R_{1}, D_{1}, B_{1}, I_{2}, R_{2}, D_{2}, B_{2}\right)$ with $I_{1}+I_{2} \geq I, D_{i} \leq A$, $B_{1}+B_{2} \leq A, R_{1}+R_{2} \leq Y_{H}$. Let $D=D_{1}+D_{2}$ and $B=B_{1}+B_{2}$ denote aggregate claims. Furthermore, we normalize notation by assuming that creditor 1 is the one with a (weakly) higher individual foreclosure right:

$$
D_{1} \geq D / 2 \geq D_{2} .
$$

Note that, once (3) is fixed, a further such normalization is not possible with respect to the collective liquidation claims $B_{i}$.

Date- 1 outcomes are payments by the firm of $(0,0)$, resp. $\left(R_{1}, R_{2}\right)$ in the two cash-flow states if there is no renegotiation, and are given by the following payment matrix if there is renegotiation:

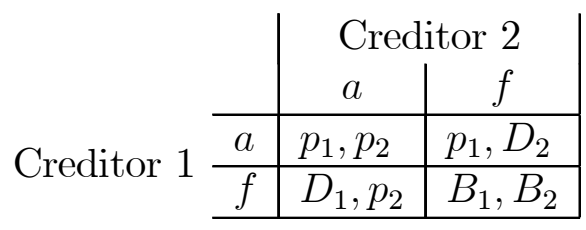

Contracts are chosen to maximize the firm's expected payoff subject to the investors' participation at date 0 . Once a contract is in place, the firm and the investors behave according to subgame-perfect Nash equilibrium, taking the contract as given. 


\section{Optimal Contracts}

We first analyze the interaction at date 1 for any given contract and then study the choice of contract at date 0 , assuming that the contracting parties anticipate how the contract influences their behavior later on. We maintain the assumption that the liquidation outcome $\left(B_{1}, B_{2}\right)$ obtains automatically if both creditors want to foreclose simultaneously in game (4). In Section 4, we investigate what game structure can achieve this ex-post outcome.

\subsection{Date 1 interaction:}

Consider first the low cash-flow state, $Y=0$. The firm has nothing to pay out, and whether or not the firm attempts to renegotiate, the payments to the creditors will be $(0,0)$ and liquidation $\left(B_{1}, B_{2}\right)$ will ensue.

Now consider the case $Y=Y_{H}$. If the firm renegotiates with both creditors, the outcome of the foreclosure game between the two creditors depends on the offered payments. We make the (standard) assumption that creditors accept the firm's payment whenever it is weakly greater than their liquidation return. A sure way for the firm to induce the outcome $(f, f)$ is to offer $p_{1}=p_{2}=0$. To prevent foreclosure by both creditors it is necessary that $p_{1} \geq D_{1}$ and $p_{2} \geq D_{2}$. If $D_{1} \geq B_{1}$ or $D_{2} \geq B_{2}$ then the firm does not have to pay more than $D_{i}$ to each creditor to obtain acceptance from both creditors. In this case, setting $p_{i}=D_{i}, i=1,2$, achieves $(a, a)$ as the unique equilibrium of the foreclosure game, and this is the cheapest way to obtain this outcome.

However, if $D_{1}<B_{1}$ and $D_{2}<B_{2}$ then setting $p_{i}=D_{i}, i=1$, 2, leads to two equilibria in game $(4),(a, a)$ and $(f, f)$. This multiplicity makes it difficult to evaluate contracts ex ante, since their value depends on what equilibrium will be played ex post. ${ }^{7}$ To simplify the analysis, we assume here that creditors play the $(a, a)$ equilibrium when being offered the payments $p_{i}=D_{i}, i=1,2$, regardless of the contract in place. ${ }^{8}$

\footnotetext{
${ }^{7}$ For a similar problem in the context of debt contracts under asymmetric information, see Gale and Hellwig (1989).

${ }^{8}$ If the creditors will play the $(f, f)$-equilibrium when being offered $p_{i}=D_{i}$, the firm must pay $p_{i}=B_{i}$ to at least one creditor in order to induce $(a, a)$. The cheapest way to achieve $(a, a)$ as the unique equilibrium outcome then is to set $p_{i}=B_{i}$ and $p_{j}=D_{j}, j \neq i$, where $B_{i}+D_{j} \leq B_{j}+D_{i}$. This yields a payoff of $Y_{H}-B_{i}-D_{j}+V$. This payoff is lower than the payoff from offering $p_{i}=D_{i}$ to both creditors, but guarantees that there is no
} 
By a similar reasoning, the firm can induce the asymmetric outcome $(a, f)$ as a unique equilibrium by offering $p_{1}=B_{1}$ and $p_{2}=0$, and analogously induce $(f, a)$ by offering $p_{1}=0$ and $p_{2}=B_{2}$. Here, the firm defaults and treats its creditors asymmetrically: it does not pay one creditor and has him collect his debt, and it pays the other creditor just enough to prevent him from sending the firm into bankruptcy. Note that such asymmetry of treatment between the two creditors is typically illegal in most jurisdictions. However, as we construct the interaction from first principles, we cannot rule out such behaviour. Rather, we shall show that optimality considerations will rule out such asymmetries.

Going back one stage in the bargaining game, which of the four bargaining outcomes in matrix (4) does the debtor want to induce when renegotiating at date $1 ?^{9}$ Clearly, this will depend on the parameters of the original contract and on the realization of $V$. As an example that we will continue below, the asymmetric default $(a, f)$ is optimal if the firm's payoff from it, $Y_{H}-B_{1}+$ $\left(1-D_{2} / A\right) V$, exceeds the payoffs from the other three alternatives, i.e. if

$$
\begin{aligned}
& Y_{H}-B_{1}+\left(1-D_{2} / A\right) V>Y_{H}-D+V \\
& Y_{H}-B_{1}+\left(1-D_{2} / A\right) V>Y_{H}+(1-B / A) V \\
& Y_{H}-B_{1}+\left(1-D_{2} / A\right) V>Y_{H}-B_{2}+\left(1-D_{1} / A\right) V
\end{aligned}
$$

These conditions are equivalent to

$$
\begin{aligned}
& \frac{V}{A}<\frac{D-B_{1}}{D-D_{1}} \\
& \frac{V}{A}>\frac{B_{1}}{B-D+D_{1}} \\
& \frac{V}{A}>\frac{2 B_{1}-B}{2 D_{1}-D}
\end{aligned}
$$

plus the condition that $D_{1}>D-B .{ }^{10}$ Hence, if these conditions are compatible, there is an intermediate range for $V$ such that asymmetric default with liquidation by creditor 2 is optimal.

\footnotetext{
liquidation.

${ }^{9}$ Of course, at date 0 management prefers the $(a, a)$ outcome because liquidation is inefficient. But at date 1 , its preferences are guided by the $D_{i}, B_{i}$, and no longer by overall efficiency considerations.

${ }^{10}$ If $D_{1} \leq D-B$ it is easy to see that the payoff from $(a, f)$ must be smaller than the payoff from $(f, f)$.
} 
Since the precise conditions under which the different choices are ex-post optimal are of little interest, we relegate their description to the appendix.

The above discussion shows that if the firm pays out to both creditors then it will not pay more than $\left(D_{1}, D_{2}\right)$. Hence, without loss of generality we can assume that the contract will not be renegotiated in this case and that $\left(R_{1}, R_{2}\right)=\left(D_{1}, D_{2}\right)$. This is consistent with our earlier definition of $D_{1}$ and $D_{2}$ as individual foreclosure rights, because in all jurisdictions we know of, an individual creditor has the right to sue the debtor for the full amount of her due debt, unless the firm seeks bankruptcy protection.

\subsection{Date 0 contracting:}

\subsubsection{Individual debt claims:}

Contract design at date 0 consists of choosing the optimal individual claims $D_{i}$ (the face values) and bankruptcy claims $B_{i}$. A first important observation is that it is never optimal to induce default and liquidation by only creditor.

Proposition 1 (Individual Debt Design): Optimal contracts satisfy

$$
\frac{D}{B} D_{1}+D-\frac{D^{2}}{B} \leq B_{1} \leq \frac{D}{B} D_{1}-D+B
$$

This implies that in equilibrium there is no asymmetric default.

The proof of Proposition 1 is given in the appendix. It states that $B_{1}, B_{2}, D_{1}, D_{2}$ must not be chosen such that the firm will want to default asymmetrically ex post, i.e. such that the firm induces the outcomes $(a, f)$ or $(f, a)$ in the renegotiation game. To see this, note that the first inequality in (8) implies that the two conditions (5) and (6) above are incompatible, hence that there is no value $V$ for which the firm wants to default asymmetrically with liquidation by creditor 2 . The second inequality in (8) analogously rules out the other asymmetric default.

The intuition for Proposition 1 is that while asymmetric default can be optimal for the debtor ex post, it is not optimal ex ante. From an ex-ante perspective, liquidation is a necessary evil in order to give the debtor incentives to repay ex post. But of course, liquidation destroys value. It is unavoidable if the debtor is liquidity constrained $(Y=0)$, and in this case assets worth $B$ are liquidated. Therefore, the classical tradeoff between lowering $B$ to 
reduce inefficiency in the bad state and increasing $B$ to improve incentives to repay in the good state is unavoidable also in this context. But partial default can only occur in the good state, and in this state default, which is strategic, should be minimized. Indeed, making the debtor repay $D_{i}$ in cash is ex ante more efficient than having her deliver $D_{i}$ through liquidation. The key insight is that this latter outcome can be avoided through the proper design of individual claims, namely by choosing individual bankrupty claims in the range defined in (8). The first inequality of (8) shows, in particular, that if creditor 1 has a high share of nominal debt (high $D_{1}$, holding total debt $D$ fixed), then his bankruptcy claim $B_{1}$ cannot be too low, either. The reason is that the contract must mute the debtor's ex-post incentive to have creditor 2 foreclose (on the relatively small $D_{2}$ ) and avoid bankruptcy by paying $B_{1}$ to creditor 1 in cash. Proposition 1 shows that this is possible for all ex-post realizations of long-term value $V$.

Note that Proposition 1 rules out the case $D_{1}<B_{1}$ and $D_{2}<B_{2}$. Hence, the optimal contract induces a unique equilibrium in the foreclosure game at date $1 .^{11}$

Proposition 1 is of interest for several reasons. First, it shows that optimal contracts treat creditors equally ex post in the sense that they do not create a situation where the debtor will want to induce unilateral foreclosure by one creditor as a means to renegotiate downward the payment to the other creditor. Under the optimal contract, either both creditors are repaid, or both are defaulted upon. Note, however, that condition (8) is compatible with heterogeneity in individual bankruptcy recovery ratios, $B_{i} / D_{i}$. The symmetry induced by the optimal contract is in line with the many provisions in different bankruptcy codes that prohibit the unequal treatment of

\footnotetext{
${ }^{11}$ Remember that we have assumed that creditors play the $(a, a)$ equilibrium when being offered the payments $p_{i}=D_{i}, i=1,2$. As noted in footnote 8 , if creditors will play the $(f, f)$-equilibrium when the contract stipulates $D_{1}<B_{1}$ and $D_{2}<B_{2}$ and the creditors are being offered $p_{i}=D_{i}$, then the firm must pay $p_{i}=B_{i}$ to at least one creditor to induce $(a, a)$. This would change the payoffs obtained under outcome $(a, a)$ to $Y_{H}-B_{i}-D_{j}+V$ and therefore invalidate the argument in the proof of Proposition 1 (which uses the payoff $Y_{H}-D+V$ for outcome $\left.(a, a)\right)$. If this is the behavior for contracts with $D_{1}<B_{1}$ and $D_{2}<B_{2}$ then it can be shown along similar lines to those in the proof of Proposition 1 that it is not optimal to set $D_{1}<B_{1}$ and $D_{2}<B_{2}$ in the first place.

Hence, no matter how the problem of multiple equilibria is solved - through the exogenous selection of one equilibrium as done here, or by assuming the worst-case scenario for the debtor, which makes him overpay - the debt structure identified in Proposition 1 is the optimal one.
} 
creditors. ${ }^{12}$ What is interesting is that the traditional justifications against unequal treatment are ethical: it is deemed unjust to treat similar creditors differently. Our model justifies such behavior on efficiency grounds: unequal treatment ex-post provides a way to pay off one creditor cheaply, which relaxes the ex-ante discipline of the liquidation threat. ${ }^{13}$

Second, the proposition shows that optimally, individual creditor claims in bankruptcy are bounded below and above. For small values of individual nominal debt $D_{i}$, the lower bound in the proposition may not bind, hence in this case optimality alone does not require debt claims to be secured in bankruptcy. Yet, if $D_{1}$ is sufficiently large (creditor 1 being the larger one by normalization), creditor 1's bankruptcy claim must be positive, and if $D_{1}$ approaches $D$ it must be almost fully secured (the lower bound for $B_{1}$ approaches $D_{1}$ ).

The third point of interest of Proposition 1 is that it shows that optimal contracts only depend on the aggregate claims $B$ and $D$, as long as individual claims respect the constraint (8). In fact, if partial liquidation is eliminated by contract design, then the firm will ex post either repay fully or go bankrupt, and this decision, to the extent that it is strategic, depends only on $B$ and $D$.

An inspection in the $D_{1}-B_{1}$ plane shows that for any level of $B$ and $D$, the set of all combinations of $B_{1}$ 's and $D_{1}$ 's that satisfy the linear inequalities $D / 2 \leq D_{1} \leq D, 0 \leq B_{1} \leq B$, and (8) is not empty, and in fact, contains a continuum of possibilities. Hence, once optimal aggregate claims $B$ and $D$ are determined, the contract cannot be pinned down further: optimal contracts are not unique in terms of individual claims $\left(D_{1}, D_{2}, B_{1}, B_{2}\right) .{ }^{14}$ Conversely, once optimal aggregate clains are determined, any combination of individual claims that satisfy the above restrictions yields an optimal contract.

\footnotetext{
${ }^{12}$ The par conditio omnium creditorum (equal treatment of all creditors) in Roman law is the mother of these clauses.

${ }^{13}$ The liquidation transfer $D_{i}$ made to the liquidating creditor $i$ can be viewed as a fraudulent conveyance, ruled out in most bankruptcy codes. A payment to one creditor is a fraudulent conveyance if it reduces the assets available to other creditors of equal or higher seniority in bankruptcy.

${ }^{14}$ Hence, our model leaves room for investor heterogeneity in the design of individual debt claims. This is in interesting extension that we do not model explicitly. We discuss some possible exogenous restrictions on individual claims, such as equal treatment in bankruptcy, in Section 4.
} 


\subsubsection{Aggregate debt claims and debt capacity}

In order to characterize the optimal aggregate claims, note that in outcome $(a, a)$ the debtor's payoff is

$$
Y_{H}-D+V
$$

while the payoff under $(f, f)$ is

$$
Y_{H}+\left(1-\frac{B}{A}\right) V
$$
iff

Comparing (9) and (10) shows that the debtor prefers $(a, a)$ over $(f, f)$

$$
\frac{D}{B} \leq \frac{V}{A}
$$

In words, if the firm is not liquidity constrained it prefers full repayment if the continuation value $V$ is higher than the threshold $D A / B$ and prefers complete strategic default otherwise. The firm gets $(1-B / A) V$ in the latter (low cash flow) state and either $Y_{H}-D+V$ (if $V \geq D A / B$ ) or $Y_{H}+(1-B / A) V$ (if $V<D A / B$ ) in the good cash flow state. Letting

$$
\theta=\operatorname{Prob}\left(V \geq \frac{D}{B} A\right),
$$

the firm's expected profit at date 0 is, therefore,

$$
\begin{aligned}
S_{0}= & (1-q)\left(1-\frac{B}{A}\right) E V+q \theta\left(Y_{H}-D+E\left[V \mid V \geq \frac{D}{B} A\right]\right) \\
& +q(1-\theta)\left(Y_{H}+\left(1-\frac{B}{A}\right) E\left[V \mid V<\frac{D}{B} A\right]\right) \\
= & q Y_{H}+E V-q \theta D-(1-q) \frac{E V}{A} B-q(1-\theta) \frac{B}{A} E\left[V \mid V<\frac{D}{B} A\right](14
\end{aligned}
$$

The last two terms of (14) show the two sources of inefficiency in the contracting problem. First, there is liquidation in the bad cash flow state (occuring with probability $1-q$ ), and second there is liquidation in the good cash flow state following strategic default (occuring with probability $q(1-\theta)$ ). The first inefficiency is minimized by making bankruptcy liquidation $B$ as small as possible. Yet, this tends to aggravate the second inefficiency, because it increases the threshold for strategic default in the last term of (14), thus making (ex ante) wasteful strategic default more likely. The optimal contract 
must strike a balance between these two payouts and the average cash payout $q \theta D$, which a priori has no negative efficiency effects but must be supported by liquidation threats to be effective.

The investors' participation constraints are

$$
(1-q) B_{i}+q \theta D_{i}+q(1-\theta) B_{i}=I_{i}, i=1,2,
$$

where the $I_{i}$ are, in fact, defined by (15), and $I_{1}+I_{2} \geq I$. Furthermore, the feasibility constraints

$$
0 \leq D_{1}, D_{2}, B_{1}, B_{2}, B \leq A
$$

and the constraints $(8)$ and $D_{1} \geq D / 2$ must hold.

Summing (15), the investors' aggregate participation constraint is

$$
(1-q \theta) B+q \theta D \geq I \text {. }
$$

Clearly, the participation constraint binds, and total borrowing is equal to investment. Hence, the contract optimization problem at date 0 is

$$
\begin{array}{cl}
\max _{D, B} & S_{0} \\
\text { s.t. } & (1-q \theta) B+q \theta D=I \\
& 0 \leq B \leq A \\
& 0 \leq D \leq 2 A .
\end{array}
$$

Here, (20) is the constraint on bankruptcy liquidation and (21) the constraint on cash payout.

The left-hand side of (19) is the equilibrium repayment to investors. Its maximum is the firm's debt capacity, i.e. the maximum money the firm can raise such that the above problem has a solution. Clearly, the firm can raise any amount $I \leq A$ by setting $B=D=I$. In this case the firm has no incentive for strategic default $(\theta=1)$ and its repayment is $I$ for sure: with probability $q$ in cash, with probability $1-q$ through bankruptcy liquidation. The interesting question is whether the firm's debt capacity can be strictly greater than its asset base.

The following estimate provides an upper bound for the debt capacity:

$$
\begin{aligned}
\max _{B, D}(1-q \theta) B+q \theta D & \leq(1-q \theta) A+2 q \theta A \\
& \leq(1+q) A
\end{aligned}
$$


This is intuitive because $(1+q) A=(1-q) A+q 2 A$ : the creditors can never get more than all assets in the bad state and cash of double that value in the good state. But (12) shows that this reasoning actually gives the exact debt capacity if $\underline{V} \geq 2 A$, i.e. if long-term firm value is always very high. In this case, increasing $B$ and $D$ all the way up to their maximum values maximises the payments to investors without creating incentives for strategic default for the debtor. On the other hand, if $\underline{V}<2 A$, the debt capacity is lower than $(1+q) A$ because the incentive for strategic default at low values of $V$ provides a countervailing effect.

Note also that if financing needs are large, individual claims must be similar: in the limit, if $I=(1+q) A$, then necessarily $D_{1}=D_{2}=D / 2$.

In order to analyze the contracting problem in greater depth, we introduce the variable $t=D / B$, the inverse of the aggregate bankruptcy recovery rate. By making appropriate substitutions and rearrangements, remembering that $\theta=1-F(A t)$, we can rewrite the contract optimization problem at date 0 as the following constrained payout minimization problem in one real variable:

$$
\begin{array}{cl}
\min _{t} & H(\varphi(t), t) \\
\text { s.t. } & t \geq 0 \\
& \varphi(t) \leq A \\
& t \varphi(t) \leq 2 A
\end{array}
$$

where

$$
H(B, t)=\left[(1-q) E V+q(1-F(A t)) A t+q \int_{0}^{A t} V d F(V)\right] B
$$

corresponds to the expected payout by the firm (which it wants to minimize) and

$$
\varphi(t)=B=\frac{I}{1+q(1-F(A t))(t-1)}
$$

uses the investors' participation constraint (19) to express bankruptcy liquidation $B$ by the new variable $t$. In the new problem, (26) corresponds to (20), and (27) to (21). The auxiliary function $\varphi$ is defined for $t \geq 0$, continuous, and is differentiable for $t>0$ except at $t=\underline{V} / A$ where it has a kink.

To simplify the presentation we assume from now on that the distribution of $V$ satisfies the Monotone Hazard Rate Condition (MHRC):

Assumption (MHRC): The hazard rate of $V, \frac{f(V)}{1-F(V)}$, is non-decreasing. 
(MHRC) is a frequent assumption in contracting problems that is met by most standard distributions. It simplifies the analysis of the present problem because it implies that the auxiliary function $\varphi$ has a unique minimum. The following lemma is proved in the appendix.

Lemma 1: Under Assumption (MHRC),

(a) $\varphi$ has exactly one minimum $t_{0}$.

(b) If $f(\underline{V})(\underline{V}-A) \geq 1$, then $t_{0}=\underline{V} / A$. Otherwise $t_{0}>\underline{V} / A$ and $\varphi^{\prime}\left(t_{0}\right)=$ 0 .

(c) $t_{0}>1$.

(d) The function $t \varphi(t)$ is strictly increasing for all $t>0$.

Comparing the two constraints of the optimization problem (24) - (27), we have $t \varphi(t) / 2<\varphi(t) \Leftrightarrow t<2$. Hence, constraint (27) on $D$ is redundant if $t<$ 2 , and constraint (26) on $B$ is redundant if $t>2$. Constraint (25) is always redundant. Since the constraint set defined by (25) - (27) is compact and the objective function is continuous, the contracting problem has a solution if and only if constraints (26) and (27) are compatible. These constraints have the investment level $I$ on their left-hand side, hence they characterize the maximum investment levels that can be financed.

Proposition 2 (Debt Capacity): The contracting problem has a solution if and only if

$$
\varphi\left(\min \left(2, t_{0}\right)\right) \leq A
$$

where $t_{0}$ is the unique minimum of $\varphi$.

Proof: If $t_{0}<2$ the two constraints are compatible iff $\varphi\left(t_{0}\right) \leq A$. If $t_{0}>2$ they are compatible iff $\varphi(2) \leq A$.

If $t_{0}>2$ condition (30) is equivalent to $\left[1+q(1-(F(2 A))] A \geq I\right.$. If $t_{0}<2$ (30) is equivalent to $\left[1+q\left(1-\left(F\left(t_{0} A\right)\right)\left(t_{0}-1\right)\right] A \geq I\right.$. Hence, because $t_{0}>1$, the firm's debt capacity is strictly greater than $A$ iff $\min \left(2, t_{0}\right) A<\bar{V}$. This reasoning also shows that the debt capacity can be as small as $A$, despite the double liquidation threat with two creditors. This is the case if the firm's long-term returns are concentrated at values close to $A$. In this case, any attempt to provide high-powered repayment incentives leads to strategic default. 


\subsubsection{Optimal contracts}

We now turn to the determination of the optimal contract, i.e. the determination of the value $t^{*}$ that solves problem (24) - (27). Remember that higher $t$ means lower bankruptcy liquidation relative to the face value of debt $D$.

Proposition 3 (Bankruptcy recovery): The solution to the minimization problem (24) - (27) satisfies $t^{*}>1$. Hence, under the optimal contract, creditors are not fully repaid in bankruptcy: $B^{*}<D^{*}$.

The proposition states that creditors should get less than the face value of their claims in bankruptcy. This result is not trivial because in the model it is quite possible to have full or even excessive recovery of claims in bankruptcy if $D<A$. Yet, our model highlights that bankruptcy liquidation has the cost of destroying value ex post, which is an effect the parties want to minimize ex ante by relying more strongly on individual liquidation threats than on aggregate ones. Proposition 3 only concerns aggregate values of debt and repayment. Individual claims will be analyzed in the next section.

Proposition 3 has an immediate consequence for the optimal number of creditors in our model. If the firm contracted with only one creditor, this creditor would hold a liquidation claim of $D$ regardless of the type of default. This implies that the creditor would be repaid $D$ in both states: in the good state in cash (because the firm prefers paying out to liquidating the same amount), and in the bad state through liquidation (because the firm is cash constrained). Such a contract can be replicated in the two creditor case by setting $D=B$ (in which case the firm never defaults strategically, just as with one creditor). Proposition 3 implies that such a contract is not optimal.

Proposition 4 (Optimal Number of Creditors): The firm strictly prefers to have two creditors rather than one.

Hence, the ability of the debtor to pledge his assets individually to more than one creditor strictly improves the terms of contracting. Because the debtor can credibly promise a higher cash payout than his bankruptcy liquidation value, the creditors can lower the amount of liquidation in bankruptcy. Although this strengthens the debtor's incentives for strategic default, these incentives are outweighed by the improved repayment incentives. The next proposition provides a sufficient condition for strategic default to occur in equilibrium. 
Proposition 5 (Strategic Default): Strategic default occurs with positive probability if

$$
f(\underline{V})(\underline{V}-A)((1-q) E V+q \underline{V})<(1-q)(E V-A)
$$

Proof: Condition (31) implies that the right-hand derivative of $H(\varphi(t), t)$ at $t=\underline{V} / A,(44)$, is strictly negative. Hence, $t^{*}>\underline{V} / A$. This implies the claim, because by (11), the firm defaults strategically iff $V<A t$.

Proposition 5 illustrates the basic tradeoff faced by the debtor. In the original two-dimensional contracting problem (18)-(21), on the one hand, minimising bankruptcy liquidation $B$ is desirable. However, the participation constraint (19) shows that this comes at the cost of increasing $t$, which means that the face value of debt $(D=t B=t \varphi(t))$ rises, which in turn favors strategic default. Yet, as long as it is possible to decrease $B$ such that $t$ does not exceed $\underline{V} / A$, strategic default is not an issue and decreasing $B$ is unambiguously advantageous. Otherwise, we have $t^{*}>\underline{V} / A$, and the contract induces some strategic default. This will happen, as condition (31) shows, if $\underline{V}$ is sufficiently small. In this case, there are some realizations of long-term firm value such that the firm prefers to keep the current cash rather than the right to future returns.

We finally investigate under what conditions the firm is not fully liquidated in bankruptcy.

Proposition 6 (Deviation from Absolute Priority): If $I<q \underline{V}+(1-$ q) A the bankruptcy liquidation constraint (20) is slack: $B^{*}<A$.

Proof: If $\underline{V} / A>2$ we have $t^{*} \geq \underline{V} / A>2$. Therefore, $\varphi\left(t^{*}\right)<\frac{t^{*}}{2} \varphi\left(t^{*}\right) \leq A$ by $(27)$.

If $\underline{V} / A \leq 2(26)$ is slack if $\varphi(\underline{V} / A)<A$, because $\varphi$ is decreasing on $\left[\underline{V} / A, t_{0}\right]$ and because of (43). This last condition is equivalent to $I<q \underline{V}+$ $(1-q) A$

Proposition 6 only provides a sufficient condition, but this suffices to make the point. The point is that the constraint on $B,(20)$ or $(26)$, does not need to bind at the optimum. If this is the case, the debtor retains some of the assets after bankruptcy. This is due to the fact that continuation in the present model is always efficient. Therefore, the parties have a strong ex ante 
incentive not to punish the debtor too hard in case of bankruptcy. However, the point continues to be true if continuing the firm ex post is efficient with a sufficiently high probabability $(\underline{V}<A$ but $F(A)$ sufficiently small), because the level of bankruptcy liquidation must be independent of $V$. Hence, only the expected continuation efficiency matters. On the other hand, if total borrowing $I$ is sufficiently high, it is optimal to make maximum use of the liquidation threat and set $B=A$.

The basic message of Proposition 6 is fairly general: if the debtor has a comparative advantage using the assets, it is ex ante costly to separate her from them ex post, and, therefore, an optimal contract will aim at reducing this incidence as much as possible. This insight, simple as it is, is in sharp contrast with traditional legal reasoning that demands to satisfy creditors first in case of bankruptcy (absolute priority). On the other hand, our model also spells out the costs of deviations from absolute priority (reduced debt capacity and increased incentives for strategic default). It is therefore consistent with the observed wide variety of practices of handling absolute priority. In particular, it may be useful in explaining the long-term decline in absolute priority violations in the U.S. observed by Bharath, Panchapegesan, and Werner (2008).

\section{Bankruptcy versus Debt Collection}

In the base model of the last section, we have assumed that a simultaneous attempt by creditors to collect their debt automatically triggers bankruptcy. In reality, of course, bankruptcy must be triggered by someone, and the base model is silent on this issue. In this section, we generalize the base model to a model in which bankruptcy is not an automatic consequence of simultaneous debt collection, but the result of deliberate individual decisions. For these decisions the individual payoffs are important, which were left largely unspecified in the optimal payment/liquidation schedule of the last section.

Proposition 1 already implies some interesting structure for individual claims.

Proposition 7 (No Over-Collateralization): The creditors' individual claims satisfy $B_{i}^{*} \leq D_{i}^{*}$ for $i=1,2$.

Proposition 7 makes a familiar but not obvious statement. From Propo- 
sition 3 we know that total bankruptcy liquidation must be strictly smaller than the total face value of debt. Proposition 7 states that this must even hold at the individual level: no single creditor must have the right to liquidate more in bankruptcy than his nominal debt claim. This is what is true in practice, but upon reflection not a priori clear. In fact, our model provides one possible reason why it might be optimal to have one creditor who is overcollateralized, i.e. who holds a bankruptcy claim $B_{i}>D_{i}$ : such a creditor would always trigger bankruptcy when the firm defaults strategically. Since bankruptcy by Proposition 3 protects the firm, this is ex ante desirable and would also have a dissuasive effect on strategic default. However, Proposition 7 also shows why such an arrangement is impossible: Giving one creditor a high bankruptcy claim would imply that the other creditor gets such a small bankruptcy claim that there are ex-post firm values $V$ for which the firm will default partially, which is not optimal ex ante.

We now generalize the contracting model of the last two sections by asking what type of interaction at date 1 can bring about the (second-best) optimal aggregate repayment/liquidation schedule $\left(B^{*}, D^{*}\right)$ if bankruptcy does not obtain automatically. For this, we must reconsider the assumption about simultaneous foreclosure in the debt collection game (4). While bankruptcy is a coordinated attempt to recover funds from the debtor in default, simultaneous foreclosure is a priori uncoordinated. Hence, instead of the collective debt collection procedure assumed in game (4) in Section 2, we will now assume that simultaneous foreclosure results in an uncoordinated run for the assets, in which the first to collect his debt liquidates $D_{i}$, and the second receives $\min \left(D_{j}, A-D_{i}\right)$ where $j \neq i$ and $i$ is the creditor who collects first. Assuming that each creditor has the same probability of being first, the payoff matrix becomes

\begin{tabular}{c|c|l|} 
& $a$ & \multicolumn{1}{|c}{} \\
\hline$a$ & $p_{1}, p_{2}$ & $p_{1}, D_{2}$ \\
\hline$f$ & $D_{1}, p_{2}$ & $\frac{1}{2} D_{1}+\frac{1}{2} \min \left(D_{1}, A-D_{2}\right), \frac{1}{2} D_{2}+\frac{1}{2} \min \left(D_{2}, A-D_{1}\right)$ \\
\hline
\end{tabular}

where $p_{1}=p_{2}=0$ in the case of $Y=0$.

In this framework, which represents a "pre-bankruptcy", primitive state, ex-post interactions and ex-ante contracting will be as in Section 3, with the exception that $B$ is fixed exogenously at $\bar{B}=\min (A, D)$. This simplifies the problem of Section 3 considerably, but, as Propositions 3 and 6 have shown, 
the resulting contract will typically not be optimal. The reason is that the deadweight loss from high liquidation in the bad state more than outweighs the improved incentives for payout in the good state. Ex ante it is therefore optimal to reduce the threat of liquidation from $\min (A, D)$ to $B^{*}$.

This can be done by introducing bankruptcy into the model; more precisely, by giving each creditor or the firm the right to trigger bankruptcy when the firm defaults on (some of) its payments. Bankruptcy then means that individual debt collection is suspended, and creditors receive $B_{i}$ instead of $D_{i}$.

The possibility of triggering bankruptcy changes nothing in the analysis of Section 3 if the firm has defaulted partially. In fact, the creditor who is defaulted upon recuperates his full claim through individual debt collection (which is individually optimal by Proposition 7), whereas the other creditor weakly prefers to accept the renegotiated payment from the firm. The firm prefers partial default to bankruptcy by revealed preferences.

If the firm has defaulted on both creditors, be it for liquidity or strategic reasons, the analysis changes. In this case, creditor $i$ when observing the attempt to foreclose by creditor $j$, will call bankruptcy if this makes him better off than waiting, i.e. if

$$
B_{i}>\min \left(D_{i}, A-D_{j}\right) .
$$

Proposition 7 implies that for optimal values of $B_{i}, D_{i}$ condition (33) is equivalent to

$$
B_{i}^{*}>A-D_{j}^{*}
$$

Since either of the two creditors may be last in line for debt collection, condition (34) must hold for $i=1,2$, if an (inefficient) run for the assets shall be avoided for sure. Adding up (34) for $i=1,2$ yields the joint condition

$$
B^{*}+D^{*}>2 A \text {. }
$$

Whether or not the optimal $\left(B^{*}, D^{*}\right)$ satisfy this condition depends on the parameters of the model. Using the definition of $\varphi$ and $t$ of the previous section, (35) is equivalent to

$$
\left(1+t^{*}\right) \varphi\left(t^{*}\right)>2 A
$$

If the optimal aggregate repayment/liquidation schedule $\left(D^{*}, B^{*}\right)$ satisfies the joint condition (35), the next question is whether one can find values 
$B_{1} \leq D_{1}$ with $D_{1} \geq D^{*} / 2$ such that (34) and the conditions (8) jointly hold. If this is the case, the solution $\left(D^{*}, B^{*}\right)$ can be implemented by giving each creditor the right to trigger bankruptcy. If this is not the case or if $B^{*}+D^{*}<2 A$, this will not be possible, and at least one creditor will have an incentive to run for the assets even if he has the right to trigger bankruptcy.

In this case, however, another simple contractual remedy is available: allowing the firm to trigger bankruptcy whenever at least one creditor tries to collect his debt. ${ }^{15}$ In fact, if $B^{*}<A$, the firm strictly prefers bankruptcy to uncoordinated liquidation. If on the other hand $B^{*}=A$, the firm is indifferent, but then there is no efficiency case for bankruptcy in the first place.

The following proposition shows that the condition $B^{*}+D^{*}>2 A$ is indeed sufficient for creditor-initiated bankruptcy to implement the optimal repayment/liquidation schedule.

Proposition 8 (Implementation): If $B^{*}+D^{*}>2 A$, the optimal repayment/ liquidation scheme $\left(B^{*}, D^{*}\right)$ can be implemented by giving each creditor the individual right to trigger bankruptcy following default. If $B^{*}+D^{*}<$ $2 A$, the firm must have the right to trigger bankruptcy.

As noted above, whether or not the optimal contract satisfies the condition $B^{*}+D^{*}>2 A$ depends on the parameters of the model. It is easy to see that both alternatives are possible. More detailed comparative statics of (36) require a more detailed analysis of the properties of $t^{*}$ derived in Section 3.2 and are not attempted here.

The no-run conditions (34) impose further restrictions on $B_{1}$ and $D_{1}$. For example, they imply that no creditor can be fully secured, i.e. that any optimal contract must satisfy $B_{i}<D_{i}, i=1,2 .{ }^{16}$ The reason is that full bankruptcy protection of one creditor would induce the other creditor not to trigger bankruptcy if the firm defaults, because he would get more from an uncoordinated liquidation than from bankruptcy. Hence, if the firm is not allowed to trigger bankruptcy, no creditor must hold safe claims. Yet, even with the restriction of the no-run conditions, optimal individual claims

\footnotetext{
${ }^{15}$ Whatever the other creditor does in this case - run for the assets trying to collect $D_{j}$ instead of $A-D_{i}$, or standing by the sidelines to collect $D_{j}$ for sure - the resulting liquidation is inefficient, and the firm has an incentive to trigger bankruptcy.

${ }^{16}$ Formally, the condition $B_{j}>A-D_{i}$ is equivalent to $B_{i}<B-A+D_{i}$ which implies $B_{i}<D_{i}$.
} 
are not pinned down uniquely, and there is some freedom to design them according to specific investor preferences (which we do not model here).

Note in particular that the restrictions on optimal individual claims imposed by Propositions 1, 7, and 8 do not rule out the possibility of treating creditors equally in bankruptcy. Since $D^{*}=t^{*} B^{*}$, identical recovery rates in bankruptcy for both creditors can (only) be achieved by setting $D_{i}=t^{*} B_{i}$ for $i=1,2$. For such individual claims, condition (8) of Proposition 1 can easily be shown to hold if and only if $B_{1}$ is chosen such that

$$
B^{*} / 2 \leq B_{1} \leq \frac{t^{*}}{t^{*}+1} B^{*}
$$

which is possible because $t^{*}>1$ by Proposition 3. If $t^{*}$ is relatively small (which means, following the discussion in Section 3.2, that long-term firm value does not exceed asset value $A$ by much), then condition (37) forces the claims of both creditors to be similar in size $\left(B_{1}\right.$ close to $\left.B^{*} / 2\right)$.

Hence, if the no-run conditions (34) are compatible with the inequalities (37), then individual claims can be designed such that creditors have the same recovery rates in bankruptcy. Otherwise (both alternatives are possible, depending on $I$ and $A$ ), the no-run conditions cannot be satisfied and the firm must have the right to trigger bankruptcy, if creditors are to be treated equally in bankruptcy. If equal treatment is desirable for reasons outside the present model, this provides a further justification for giving borrowers the right to trigger bankruptcy.

Proposition 8 is interesting because it provides a new efficiency justification for debtor-friendly bankruptcy rules. There is a broad consensus in academia and practice that creditors should have the right to trigger bankruptcy. The consensus is less developed with respect to debtor rights. While most of the criticism of debtor-friendly rules concerns debtor-in-possession rules such as those of Chapter 11 in the U.S., it could be argued that the individual right of a debtor to evade the discipline of debt collection is harmful. Proposition 8 shows that there is an efficiency reason for such a right: if the creditors do not have the ex-post incentives to select the efficient continuation decision, the debtor may have these incentives. Hence, any reform of possibly excessive managerial discretion rights under Chapter 11 should be careful not to throw out the child with the bathwater and scrap the debtor's right to trigger bankruptcy. ${ }^{17}$

\footnotetext{
${ }^{17}$ On a related note, see Berkovitch, Israel and Zender (1998) and Povel (1999). An excellent discussion of the initiation problem in bankruptcy is given by Baird (1991).
} 


\section{Conclusion}

We have analyzed the design of bankruptcy rules and debt structure in an optimal-contracting perspective. If cash flow is not verifiable and only the asset value of the firm is verifiable, then when a firm borrows from a single creditor and has all bargaining power, its debt capacity is limited to the value of its asset base. The reason is that the creditor can never expect to receive more than the asset value in liquidation and in renegotiation. However, when a firm borrows from more than one creditor, it can increase its debt capacity by pledging its asset base to more than one creditor by giving each the right to foreclose individually. If the debt structure of the firm is designed appropriately, the resulting non-cooperative game between creditors ex post creates a commitment for the firm to pay out more in good states to prevent the exercise of individual foreclosure rights and thus raises the firm's debt capacity. Having multiple creditors thus helps to reduce the negative effects of the lack of commitment in contracting by distinguishing between individual foreclosure rights and joint liquidation rights achieved under bankruptcy.

Our theory provides a bridge between corporate finance and the legal theory of debtor-creditor law. The key distinction in debtor-creditor law in most jurisdictions is that between debt collection law and bankruptcy law. The former governs the interaction between the debtor and a single creditor, the latter the interaction between the debtor and several creditors. ${ }^{18}$ Our analysis shows how this same distinction can be made in a contracttheoretic approach to debt. Individual foreclosure rights (corresponding to debt-collection law) are crucial to generate repayment incentives, but need to be complemented by collective liquidiation rights (corresponding to bankruptcy law) in order to maximize ex-post efficiency.

Our results on debt structure and overleverage under multiple creditors depend on the fact that creditors have unilateral foreclosure rights that they can exercise in case of default, independently of what other creditors decide. These rights should be seen as an important element of investor protection. The renegotiation procedure modeled in this paper emphasises the effect of these rights since renegotiation is assumed to happen on an individual basis. The ensuing non-cooperative game between creditors forces the debtor to

\footnotetext{
${ }^{18}$ The U.S. is a particularly telling example of this distinction. Here, the two bodies of law are even governed by different authorities: debt-collection law is state law, bankruptcy law is federal law.
} 
respect contractual claims as given by individual foreclosure rights whenever he wants to avoid default. The key assumption in this approach is that it is difficult and costly to bring the creditors together to renegotiate the debt contract collectively. Only bankruptcy brings all the contracting parties together at one table, but in bankruptcy the debtor has given up his residual ownership rights, and the procedure is mostly concerned with the reconciliation of individual liquidation claims. This is the classical "vis attractiva" of bankruptcy. ${ }^{19}$

Yet, it is theoretically conceivable that the debtor can unite the group of creditors and extract from them joint concessions under the threat of bankruptcy. If such workouts are frictionless, debt structure becomes irrelevant, because individual collection rights have no bite in enforcing claims. As documented, e.g., by Asquith, Gertner, and Scharfstein (1994) and Gilson (1997), however, frictions in such negotiations are usually substantial and increase with the number of creditors. One important reason for these frictions is the hold-up problem of individual creditors, which is precisely the reason for institutionalised bankruptcy rules as discussed in Section 4. Further reasons (which we ignore in this paper) include the aggregation of asymmetric information among multiple creditors and the legal uncertainty accompanying out-of-court debt renegotiations, if individual creditors have the possibility of contesting the new arrangement in court.

Our model has been kept deliberately simple and parsimonious. The assumption that long-term asset value $V$ is not verifiable has allowed us to focus solely on short-term debt contracts. In a more general model, $V$ would have a verifiable and an unverifiable component. The verifiable component would give rise to long-term debt and to the possibility to reschedule shortterm debt in debt renegotiation. The assumption that $\underline{V} \geq A$ has focused the analysis on the case of efficient ex-post continuation. In the more general case $\underline{V}<A$ (analyzed in the appendix) there are situations in which ex post there is no conflict of interest and the only question is how to divide the liquidation value of the firm. None of the insights of the analysis are changed, but the analysis becomes more complicated.

The analysis has been confined to the case of two creditors. To what ex-

\footnotetext{
${ }^{19}$ The notion of "vis attractiva" ("attracting force") is one of the classical principles of bankruptcy theory going back to Roman times. It formulates the historical experience that creditors typically fail to reach agreement when left to their own devices, and that only bankruptcy - when the debtor gives up the right to his estate - has the force to bring them together.
} 
tent would our insights generalize to more than two creditors? The analysis would become more complicated because now contracts have to specify what each creditor gets in liquidation for every subset of creditors who choose to foreclose in the renegotiation game. Yet, in most simple extensions of our foreclosure game creditors would still have the incentive to liquidate individually if they are not paid their face value and all others do not liquidate. Hence, the basic logic of our model applies, and our analysis suggests that more creditors are better able to extract higher repayments ex post. Of course, with many creditors, the simplifying assumption (2) of no liquidity constraints becomes unreasonable. Now the optimal number of creditors should emerge from trading off higher ex-post extraction in good states, up to the point where liquidity is exhausted, against more inefficient liquidation in bad states. Avoiding ex post asymmetric default would still be optimal for fundamentally the same reason as with two creditors even though the analysis would be more complicated. The extension of Propositions 7 and 8 to more than two creditors would also follow the same logic as in the case of two creditors. But a full analysis of the many-creditor case is beyond the scope of this paper.

In our model, all results are derived as parts of an optimal ex-ante contract between debtor and creditors. Strictly speaking this suggests that there is no need for a law. In practice, however, there may well be, if individuals are unable to join the initial grand contract and write contracts specifying procedures of collective behavior. In fact, this is the classical Rawlsian justification of legislation as a substitute for contracting in the "original position" (Rawls, 1971), an approach to law, and bankruptcy law in particular, that is wide-spread in legal thinking. ${ }^{20}$ The classic text of Jackson (1986), for example, when exploring the foundations of bankruptcy law, only argues that a "collective system of debt collection law" is needed, relegating the issue of private contracting to a footnote. ${ }^{21}$ Building on this approach to the foundations of bankruptcy law, our contribution is to make the hypothetical private contract explicit.

The role for a law in our model therefore is that of a general rule that completes individual incomplete contracts (which are mostly concerned with individual financial claims such as the $I_{i}$ and $R_{i}$ ), when these contracts cannot

\footnotetext{
${ }^{20}$ See, e.g., Schwartz (1998) and more generally Schwartz and Scott (2003).

21 "As such, it reflects the kind of contract that creditors would agree to if they were able to negotiate with each other before extending credit" (Jackson, 1986, p. 17).
} 
be executed in isolation. Going one step further, there is also an intersting role for bankruptcy courts in our model. One obvious such role of bankruptcy courts with great practical importance is that of a certification agency that verifies the firm's asset value $A$ and the outstanding claims against the firm. We have gone beyond that and shown that courts are important in imposing an automatic stay to prevent a run for the assets and supervise the contractually agreed collective liquidation procedure. In fact, our model shows that there is an important conceptual distinction between out-of-bankruptcy negotiations and bankruptcy. These two events are both inefficient ex-post, but for different reasons: negotiations out of bankruptcy are inefficient because the parties have difficulties to coordinate and avoid free-riding. Bankruptcy has no coordination costs because the law forces the parties around one table, but since the court enforces the liquidation promise of the original contract, asset value is destroyed inefficiently. Going one step further, in our model courts can also have a role in determining the distribution of the asset value to the creditors. As we have argued, it is difficult in practice to fix bankruptcy payouts $B_{i}$ contractually because not everybody has joined the initial grand contract. Hence, these payouts must be set ex-post in a situation of widely diverging interests. Our model provides guidelines of the type $B_{i}=g_{i}\left(D_{1}, D_{2}, I_{1}, I_{2}\right)$ that determine bankruptcy payments as a function of nominal claims. Note that aggregate bankruptcy payout in our model is linked to total debt by $B=\varphi\left(\psi^{-1}(D)\right)$ where $\psi(t)=t \varphi(t)$ (which is strictly monotone by Lemma 1). Bankruptcy courts can use this type of relation to implement rules for individual payments.

Another line of research to develop our model further is to analyze the effect of different renegotiation procedures. We have considered a fixed bargaining game between debtor and creditors, and analyzed its implications for debt structure and bankruptcy. This bargaining game, bilateral exchange offers, captures some important features and frictions of debt renegotiations, but, in the spirit of Harris and Raviv (1995), it would be useful to compare this structure to others. For these and other extensions, our model may be a useful building block that allows to develop a more comprehensive theory of bankruptcy and ultimately contribute to a broader comparative analysis of the workings and effects of different bankruptcy laws. 


\section{Appendix}

\subsection{Proofs}

\section{Proof of Proposition 1:}

As discussed in the main text, at the renegotiation stage the firm has four alternatives that lead to the following payoffs. Under outcome $(a, a)$, the payoff is $Y_{H}-D+V$. Under outcome $(f, f)$ it is $Y_{H}+(1-B / A) V$. Under outcome $(f, a)$ it is $Y_{H}-B_{2}+\left(1-\frac{D_{1}}{A}\right) V$, and under $(a, f) Y_{H}-B_{1}+\left(1-\frac{D_{2}}{A}\right) V$. By some straightforward but lengthy comparisons it can be shown that the firm's choice is, in fact, quite well structured. We summarize this choice in the following Lemma.

Lemma A1: The renegotiation game at date 1 has the following outcomes:

1. If

$$
B_{1}>\frac{D}{B} D_{1}-D+B
$$

the firm optimally induces

- outcome $(a, a)$ if and only if $\frac{V}{A} \geq \frac{D-B+B_{1}}{D_{1}}$

- outcome $(f, a)$ if and only if $\frac{B-B_{1}}{B-D_{1}} \leq \frac{V}{A}<\frac{D-B+B_{1}}{D_{1}}$

- outcome $(f, f)$ if and only if $\frac{V}{A}<\frac{B-B_{1}}{B-D_{1}}$

2. If

$$
B_{1}<\frac{D}{B} D_{1}+D-\frac{D^{2}}{B}
$$

the firm optimally induces

- outcome $(a, a)$ if and only if $\frac{V}{A} \geq \frac{D-B_{1}}{D-D_{1}}$

- outcome $(a, f)$ if and only if $\frac{B_{1}}{B-D+D_{1}} \leq \frac{V}{A}<\frac{D-B_{1}}{D-D_{1}}$

- outcome $(f, f)$ if and only if $\frac{V}{A}<\frac{B_{1}}{B-D+D_{1}}$

3. If $\frac{D}{B} D_{1}+D-\frac{D^{2}}{B} \leq B_{1} \leq \frac{D}{B} D_{1}-D+B$ the firm optimally induces

- outcome (a,a) if and only if $\frac{V}{A} \geq \frac{D}{B}$

- outcome $(f, f)$ if and only if $\frac{V}{A}<\frac{D}{B}$. 
The lemma states that the firm will default against both creditors if future firm value is low, it will repay both creditors $\left(D_{1}, D_{2}\right)$ in cash if future firm value is high, and it will default partially in an intermediate region. This intermediate region is empty in the third case. Note that the condition in this third case is condition (8) of Proposition 1.

We now show that it is not optimal to choose individual claims according to condition (39). Define the two bounds derived in Lemma A1 for the case (39) as $V_{L}=\frac{B_{1}}{B-D+D_{1}} A$ and $V_{H}=\frac{D-B_{1}}{D-D_{1}} A$. We now take an arbitrary combination $\left(B, D, B_{1}, D_{1}\right)$ that satisfies (39) and vary $B_{1}, D_{1}$ for $0<B_{1}<$ $B$ and $\frac{B}{D} B_{1}+D-B<D_{1}<D$ such that the investors stay on their participation constraint.

The investors' (aggregate) participation constraint is

$$
\left(1-q+q F\left(V_{L}\right)\right) B+q\left(1-F\left(V_{H}\right)\right) D+q\left(F\left(V_{H}\right)-F\left(V_{L}\right)\right)\left(B_{1}+D-D_{1}\right)=I .
$$

Hence, small changes $d B_{1}$ and $d D_{1}$ keep the investors indifferent iff $\left(F\left(V_{H}\right)-F\left(V_{L}\right)\right)\left(d B_{1}-d D_{1}\right)=\left(D_{1}-B_{1}\right) f\left(V_{H}\right) d V_{H}+\left(D-B-D_{1}+B_{1}\right) f\left(V_{L}\right) d V_{L}$

where $d V_{i}=\partial_{B_{1}} V_{i} d B_{1}+\partial_{D_{1}} V_{i} d D_{1}$.

The total ex-ante deadweight loss under any choice $\left(D_{1}, B_{1}\right)$ is

$$
\begin{aligned}
L= & q\left[\int_{\underline{V}}^{V_{L}}\left(\frac{B}{A} V-B\right) d F(V)+\int_{V_{L}}^{V_{H}}\left(\frac{D-D_{1}}{A} V-\left(D-D_{1}\right)\right) d F(V)\right] \\
& +(1-q)\left(\frac{B}{A} E V-B\right)
\end{aligned}
$$

(remember that cash transfers constitute no loss). Hence, under the small change $\left(d D_{1}, d B_{1}\right)$ we have, after some manipulations,

$$
\begin{aligned}
\frac{1}{q} d L= & \left(D-D_{1}\right)\left(\frac{V_{H}}{A}-1\right) f\left(V_{H}\right) d V_{H}+\left(B+D_{1}-D\right)\left(\frac{V_{L}}{A}-1\right) f\left(V_{L}\right) d V_{L} \\
& +\left(F\left(V_{H}\right)-F\left(V_{L}\right)-\int_{V_{L}}^{V_{H}} \frac{V}{A} d F(V)\right) d D_{1} \\
= & \left(D-D_{1}\right)\left(\frac{V_{H}}{A}-1\right) f\left(V_{H}\right) d V_{H}+\left(B+D_{1}-D\right)\left(\frac{V_{L}}{A}-1\right) f\left(V_{L}\right) d V_{L} \\
& -\left(\left(\frac{V_{H}}{A}-1\right) F\left(V_{H}\right)-\left(\frac{V_{L}}{A}-1\right) F\left(V_{L}\right)-\frac{1}{A} \int_{V_{L}}^{V_{H}} F(V) d V\right) d D_{1}
\end{aligned}
$$


where we have used partial integration for the last equality. Combining the last formula with (41) shows, after some straightforward manipulations, that increasing $D_{1}$ strictly increases $L$ if (39) holds. Therefore and since (39) is a strict inequality, decreasing $D_{1}$ increases ex-ante value, and the contract satisfying (39) is not optimal.

A similar argument shows that (38) is not possible under an optimal contract.

Proof of Lemma 1: For $t<\underline{V} / A, \varphi$ is strictly decreasing. For $t>\underline{V} / A$, the derivative of $\varphi$ is

$$
\varphi^{\prime}(t)=-\frac{1-F(A t)-A f(A t)(t-1)}{(1+q(1-F(A t))(t-1))^{2}} q I
$$

This derivative is negative iff

$$
\frac{f(A t)}{1-F(A t)}<\frac{1}{A t-A}
$$

Hence, (MHRC) implies statements (a) and (b).

If $f(\underline{V})(\underline{V}-A)<1$, (b) implies that $t_{0}>\underline{V} / A \geq 1$. If $f(\underline{V})(\underline{V}-A) \geq 1$, then $\underline{V}>A$, hence $t_{0}=\underline{V} / A>1$, which proves (c).

Statement $(\mathrm{d})$ follows by differentiation for $t \neq \underline{V} / A$

Proof of Proposition 3: It is easy to check that both partial derivatives of the objective function $H$ are positive:

$$
\begin{aligned}
H_{B}(B, t) & =(1-q) E V+q(1-F(A t)) A t+q \int_{0}^{A t} V d F(V)>0 \\
H_{t}(B, t) & =q A B(1-F(A t)) \geq 0
\end{aligned}
$$

This is intuitive: increasing collective liquidation $(B)$ and total payout obligations $(D=t \varphi(t)$, which is increasing in $t$ by Lemma 1-(d), reduces the firm's profit. Given that $t_{0}$ is the unique minimum of $\varphi$, this implies that $\frac{d}{d t} H(\varphi(t), t)>0$ if $t>t_{0}$. Hence, the solution to the minimization problem (24) - (27) satisfies $t^{*} \leq t_{0}$. Furthermore, by explicit calculation one finds that for $t<\underline{V} / A$ (which implies $F(A t)=f(A t)=0$ ),

$$
\frac{d}{d t} H(\varphi(t), t)=-\frac{q(1-q) I}{(1+q(t-1))^{2}}[E V-A]<0
$$


This implies that the solution satisfies

$$
\underline{V} / A \leq t^{*} \leq t_{0}
$$

If $\underline{V}>A$, (43) implies the desired result. If $\underline{V}=A$ we have $t^{*}>1 \mathrm{iff}$ the right-hand derivative of $H(\varphi(t), t)$ at $\underline{V} / A$ is strictly negative. Direct calculation shows that this derivative is

$$
\frac{q A^{2} I}{(A+q(\underline{V}-A))^{2}}[A+q(\underline{V}-A)-((1-q) E V+q \underline{V})(1-f(\underline{V})(\underline{V}-A))]
$$

For $\underline{V}=A$, this derivative is $-q(1-q) I[E V-A]<0$, which proves the proposition.

Proof of Proposition 7: By Proposition 1, $B_{1}^{*}, D_{1}^{*}, B^{*}, D^{*}$ must satisfy constraint (8). Suppose first that $B_{1}^{*}>D_{1}^{*}$. Then (8) implies $D_{1}^{*}<\frac{D^{*}}{B^{*}} D_{1}^{*}-$ $D^{*}+B^{*}$ which is equivalent to $D_{1}^{*}>B^{*}$. Hence, $D_{1}^{*}>B_{1}^{*}$, a contradiction. Now suppose that $B_{2}^{*}>D_{2}^{*}$. This is equivalent to $B_{1}^{*}<D_{1}^{*}-D^{*}+B^{*}$. Now (8) implies $D_{1}^{*}<D^{*}-B^{*}$, which implies $B_{1}^{*}<0$, a contradiction.

Proof of Proposition 8: Assume that $B^{*}+D^{*}>2 A$. Because $B^{*} \leq A$ (feasibility), this condition immediately implies $D^{*}>A$. As argued in the main text, if none of the two creditors shall prefer a run to bankruptcy, we must have

$$
\begin{aligned}
& B_{1}>A-D^{*}+D_{1} \\
& B_{1}<B^{*}-A+D_{1} .
\end{aligned}
$$

A straightforward geometrical argument in the $D_{1}-B_{1}$ plane (for $B^{*}$ and $D^{*}$ fixed) shows that conditions (45) and (46) are consistent with condition (8), which we know from Proposition 1 an optimal contract must satisfy. For this argument it is helpful to distinguish between the cases $D^{*}>2 B^{*}$ and $B^{*}<D^{*} \leq 2 B^{*}$. Figure 1 shows the case $B^{*}<D^{*} \leq 2 B^{*}$ : the shaded area represents condition (8) together with the restrictions $D_{1} \geq D^{*} / 2$ and $B_{1} \leq B^{*}$.

\subsection{Inefficient continuation: the case $V<A$}

We now briefly sketch how the analysis changes if the continuation of the firm can be inefficient ex post. Hence, we replace assumption (1) by the assumption $\underline{V}<A<\bar{V}$. 


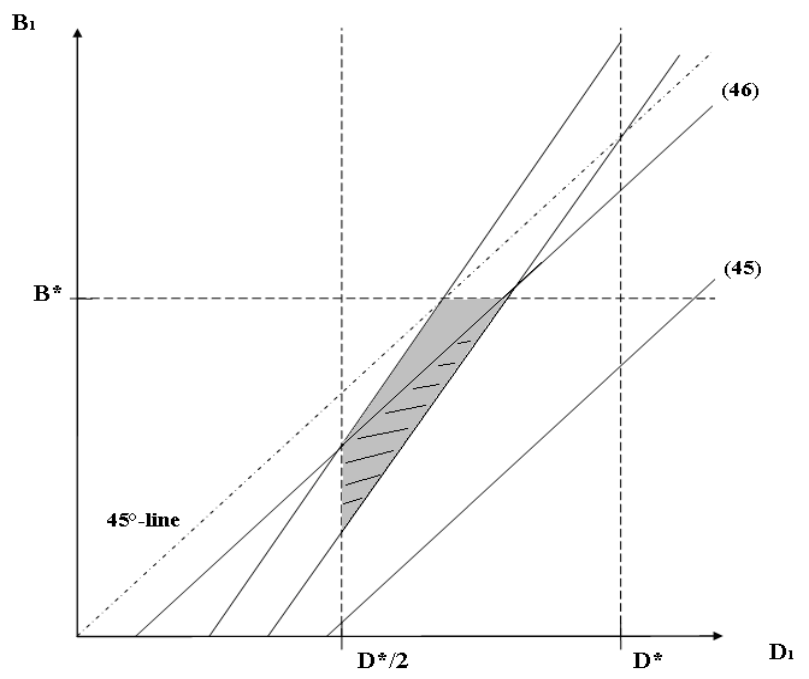

Figure 1: Consistency of conditions (45) and (46)

The main results do not change in this setting. However, some of the analysis becomes more complicated. Already Lemma A1 changes significantly, which reflects the different continuation incentives when $V<A$. In fact, the main insight for the case $V<A$ is that the debtor will always liquidate all his assets voluntarily ex post. This means that the debtor values an asset loss exactly like a cash loss. In particular, if $V<A$ the debtor prefers repayment (the cell $(a, a)$ ) over strategic bankruptcy (the cell $(f, f)$ ) iff $D<B$. This condition, and the analogous ones for asymmtric default, are different from the conditions in Lemma A1 and must therefore be added to the (already complicated) set of conditions in Lemma A1. However, a closer inspection shows that for the case of regime 3 (no partial liquidation), defined by (8), the additional restrictions mean very little. More precisely, if $D>B$, the default condition in regime 3 remains unchanged (i.e., the new conditions are slack); and for $D<B$, it becomes even simpler, becaus there never is strategic default.

Proposition 1 does not change at all when $\underline{V}<A$. The reason for why regime 3 is optimal ex ante is essentially the same as before: As seen in Proposition 1, it is strictly suboptimal to induce partial liquidation when $V>A$ for sure, because it induces too much liquidation compared to what 
it achieves on the incentives front. However, if $V<A$ ex post, liquidation is efficient and the parties are therefore indifferent ex ante whether to induce partial liquidation or not. Hence, as long as there is some probability that $V>A$, the parties will strictly prefer to induce regime 3 .

For the analysis of Propositions $2-6$, one additional argument is necessary when $\underline{V}<A$. As seen above, if $D<B$ the debtor will always repay $D$ when solvent (regardless of $V$ ). Hence, there is no concern with strategic bankruptcy ex ante. This implies that it is optimal to increase $D$ at the margin (which is costless in terms of incentives and liquidation loss) and lower $B$ in exchange (which brings an efficiency gain if $V>A$ ex post). It follows that the optimal contract has $D \geq B$.

This now implies that the analysis remains essentially unchanged in the more general model. In fact, the debtor will default strategically if $V<A$ (because this costs him cash of $B$ instead of cash of $D$ - remember that he transforms his assets into cash, anyhow), and will default strategically if $A \leq V<t A$ (for the reasons discussed in Section 3.1). Taken together this means that the debtor will default strategically iff $V<t A$, exactly as before. The debtor's ex ante objective therefore is to maximize

$$
\begin{aligned}
& (1-q) F(A)(A-B)+(1-q) \int_{A}^{\bar{V}}\left(1-\frac{B}{A}\right) V d F(V)+q F(A)(Y+A-B) \\
& +q \int_{A}^{A t} Y+\left(1-\frac{B}{A}\right) V d F(V)+q \int_{A t}^{\bar{V}} Y-D+V d F(V)
\end{aligned}
$$

which is a direct generalization of $S_{0}$ in (13). Hence, the deadweight loss to be minimized is

$$
H(B, t)=\left[K+(1-F(A t)) A t+\int_{A}^{A t} V d F(V)\right] B
$$

where

$$
K=\frac{F(A)}{q} A+\frac{1-q}{q} \int_{A}^{\bar{V}} V d F(V)
$$

The function $H$ as defined in (47) is exactly the same as in (28), taking into account that $F(A)=0$ in the case of Section 3.2 and that liquidation for $V<A$ is no deadweight loss. Similarly, the participation constraint does not change at all, and therefore, the $\varphi$ - function linking $B$ and $t$ remains unchanged in the more general framework. Hence, the analysis can be conducted as before. Intuitively, what happens is that all the realizations $V<A$ 
lead to voluntary liquidation by the debtor, which gives him verifiable funds of $A$. This is the same as assuming that the distribution of $V$ has $\underline{V}=A$ with a mass point at $A$.

Put differently, liquidation is efficient for $V<A$ and inefficient for $V>A$. In the former case, liquidation by the creditors simply is a transfer, with no ex-post efficiency consequences. Qualitatively, in the design of the initial contract, the efficiency consideration of the case $\underline{V} \geq A$ is therefore the only one that matters. Quantitatively, shifting weight in the distribution of $V$ to the left of $A$ will, of course, change things. For example, an inspection of the $\varphi$ - function in (29) shows that this shift will shift $\varphi$ uniformly upward. But this is only to be expected: if the firm's prospects become worse, its debt capacity goes down, and its bankruptcy loss will increase. 


\section{References}

Acharya, V. K. John, and R. Sundaram (2010), "Cross-Country Variations in Capital Structure: The Role of Bankruptcy Codes", Journal of Financial Intermediation, forthcoming.

Asquith, P., R. Gertner and D. Scharfstein (1994), "Anatomy of Financial Distress: An Examination of Junk Bond Issuers", Quarterly Journal of Economics 109, 625-658.

Aghion, Ph., Hart, O. and J. Moore (1992), "The Economics of Bankruptcy Reform", Journal of Law, Economics and Organization 8, 523-46.

Baird, D. (1991), "The Initiation Problem in Bankruptcy", International Review of Law and Economics 11, 223-232.

Baird, D. and D. Bernstein (2005), "Absolute Priority, Valuation Uncertainty, and the Reorganization Bargain", mimeo, University of Chicago Law School.

Bebchuk, L. (1988), "A New Approach to Corporate Reorganizations" Harvard Law Review 101, 775-804.

Bebchuk, L. (2002), "Ex-ante Costs of Violating Absolute Priority in Bankruptcy", Journal of Finance 57, 445-460.

Berglöf, E. and E.L. von Thadden, (1994), "Short-Term Versus Long-Term Interests : Capital Structure with Multiple Investors", Quarterly Journal of Economics 109, 1055-84.

Berkovitch, E. and R. Israel (1999), "Optimal Bankruptcy Laws across Different Economic Systems", Review of Financial Studies 12, 347-77.

Berkovitch, E., R. Israel and J. Zender (1998), "The Design of Bankruptcy Law: A Case for Management Bias in Bankruptcy Procedures," Journal of Financial and Quantitative Analysis 33, 441-64.

Bharath, S., V. Panchapegesan, and I. Werner (2008), "The Changing Nature of Chapter 11", manuscript, University of Michigan.

Bisin, A. and A. Rampini (2006), "Exclusive Contracts and the Institution of Bankruptcy", Economic Theory 27, 277-304.

Bolton, P. and D. Scharfstein (1996), "Optimal Debt Structure with Multiple Creditors", Journal of Political Economy 104, 1-25.

Bris, A. and I. Welch (2005), "The Optimal Concentration of Creditors", Journal of Finance 60, 2193-2212. 
Cornelli, F. and L. Felli (1997), "Ex-ante Efficiency of Bankruptcy Procedures", European Economic Review 41, 475-85.

Davydenko, S. (2005), "When Do Firms Default? A Study of the Default Boundary" manuscript, Rotman School of Management, University of Toronto.

Detriagache, E. and P. Garella (1996), "Debt Restructuring with Multiple Creditors and the Role of Exchange Offers", Journal of Financial Intermediation 5, 305-336.

Dewatripont, M. and J. Tirole (1994), "A Theory of Debt and Equity: Diversity of Securities and Manager-Shareholder Congruence", Quarterly Journal of Economics 109, 1027-1054.

Franks, J. and W. Torous (1989), "An Empirical Investigation of U.S. Firms in Renegotiation", Journal of Finance 44, 747-769.

Gale, D. and M. Hellwig (1985), "Incentive-Compatible Debt Contracts: The One-Period Problem", Review of Economic Studies 52, 647-663.

Gale, D. and M. Hellwig (1989), "Repudiation and Renegotiation: The Case of Sovereign Debt", International Economic Review 30, 3-31.

Gertner, R. and D. Scharfstein (1991), "A Theory of Workouts and the Effects of Reorganization Law", Journal of Finance 46, 1189-1222.

Gilson, S. (1997), "Transactions Costs and Capital Structure Choice: Evidence from Financially Distressed Firms", Journal of Finance 52, 161-196.

Gilson, S., K. John and L. Lang (1990), "Troubled Debt Restructuring: An Empirical Study of Private Reorganization of Firms in Default", Journal of Financial Economics 27, 315-353.

Hackbart, D., C. Hennessy and H. Leland (2007), "Can the Tradeoff Theory Explain Debt Structure?", Review of Financial Studies 20, 1389-1428.

Harris, M and A. Raviv (1995), "The Role of Games in Security Design", Review of Financial Studies 8, 327-367.

Hart, O. (1995), Firms, Contracts and Financial Structure, Clarendon Lectures in Economics, Oxford University Press, Oxford.

Hart, O. and J. Moore (1998), "Default and Renegotiation: A Dynamic Model of Debt", Quarterly Journal of Economics 113, 1-41.

Hege, U. and P. Mella-Barral (2005), "Repeated Dilution of Diffusely Held Debt", Journal of Business 78, 737-786. 
Jackson, T. (1986), The Logic and Limits of Bankruptcy Law, Harvard University Press, Cambridge, Massachussetts.

Kordana, K. and E. Posner (1999), "A Positive Theory of Chapter 11," New York University Law Review 74, 161-234.

Povel, P. (1999) "Optimal 'Soft' or 'Tough' Bankruptcy Procedures ", Journal of Law Economics $\&$ Organization 15, 659-84.

Rawls, J. (1971), A Theory of Justice, Harvard University Press.

Schwartz, A. (1998), "A Contract Theory Approach to Business Bankruptcy", Yale Law Journal 107, pp. 1806-1851.

Schwartz, A. and R. Scott (2003), "Contract Theory and the Limits of Contract Law", Yale Law Journal 113,

Townsend, R. (1979), "Optimal Contracts and Competitive Markets with Costly State Verification", Journal of Economic Theory 21, 265-293.

Weiss, L. (1990), "Bankruptcy Resolution: Direct Costs and Violation of Priority of Claims", Journal of Financial Economics 27, 285-314.

Winton, A. (1995), "Costly State Verification and Multiple Investors: The Role of Seniority", Review of Financial Studies 8, 91-123. 